\title{
Periportal fibrosis and other liver ultrasonography findings in vinyl chloride workers
}

\author{
M Maroni, F Mocci, S Visentin, G Preti, A C Fanetti
}

Occup Environ Med 2003;60:60-65

\begin{abstract}
Aims: To investigate the presence of liver lesions and their relation with vinyl chloride monomer (VCM) exposure or other personal risk factors, in workers involved in the production of VCM and polyvinyl chloride (PVC).

Methods: A liver ultrasonography examination was conducted in 757 workers, some of whom had long standing service in the production of VCM and PVC. The study involved: assessment of individual past and present VCM exposure of each worker; collection of past personal health history, lifestyle and personal data; routine liver function tests; and liver ultrasonography. Results: No cases of liver malignancies were detected. Angiomas and liver cysts were found with a frequency of occurrence within the expected range of the general population. The main findings consisted of hepatomegaly $(34.7 \%)$, steatosis $(31.8 \%)$, and periportal fibrosis $(16.0 \%)$. A logistic regression analysis indicated that hepatomegaly and steatosis were associated with obesity and lipid metabolism disturbances and not with VCM exposure. Periportal fibrosis, in addition to constitutional or dietary factors, was shown to be associated with VCM exposure, but only when maximum exposure in the subject's history had been at least 200 ppm as a yearly average; no effects were observed at 50 ppm or below.

Conclusions: Workers exposed to 200 ppm VCM for at least one year have a fourfold increased risk of developing periportal liver fibrosis. Liver ultrasonography is a suitable and important diagnostic test for the medical surveillance of vinyl chloride workers.
\end{abstract}

See end of article for authors' affiliations

Correspondence to: Department of

Occupational Medicine, University of Milan, Via Magenta 25, 20020 Busto Garolfo, Milan, Italy; mmaroni@icps.it

Accepted 5 June 2002

\section{SUBJECTS AND METHODS}

\section{Design of the study}

Four VCM/PVC plants, respectively located in Porto Marghera, Ravenna, Brindisi, and Porto Torres and all belonging to the same company (European Vinyls Corporation Italia SpA (EVC Italia)), were in operation in Italy in 1998 with a total workforce of about 760 workers. In agreement with the national and local trade unions, the management of the com-

pany promoted the execution of the ultrasonography study in 1998. The study was planned in 1997 and carried out in 1998.

After information was given about the study purpose and programme, each worker was asked to participate and sign an informed consent. In total, 757 workers agreed to participate.

The programme of the study included the following:

(1) Inventory of the work history of each worker and assessment of individual past and present VCM exposure.

(2) Collection of past personal health history, lifestyle and personal data, and execution of routine liver laboratory tests.

(3) Liver ultrasonography.

Inventory of the work history of each worker and assessment of individual past and present VCM exposure

This activity was carried out together with the industrial hygiene and personnel units of EVC Italia. After reconstructing the individual work history of each worker, VCM exposure levels before 1983 were attributed to each subject on the basis of his/her job and plant, using the estimated values assigned to the various jobs by an epidemiological survey coordinated by the National Institute of Health of Italy on the workers exposed until $1985 .^{2}$

For the period 1983-98, VCM exposure levels were obtained from the measurements provided by the fixed environmental monitoring systems operating in the plants since the early 1980s. These systems provide a measurement of the VCM

Abbreviations: $A L T$, serum alanine aminotransferase; $A P$, serum alkaline phosphatase; AST, serum aspartate aminotransferase; BMI, body mass index; GGT, serum $\gamma$ glutamyl transferase; PVC, polyvinyl chloride; VCM, vinyl chloride monomer 


\begin{tabular}{|c|c|c|c|c|c|c|c|c|c|c|}
\hline & \multicolumn{10}{|c|}{ Factory } \\
\hline & \multicolumn{2}{|c|}{ Porto Torres } & \multicolumn{2}{|c|}{ Brindisi } & \multicolumn{2}{|c|}{ Ravenna } & \multicolumn{2}{|c|}{ Porto Marghera } & \multicolumn{2}{|l|}{ Total } \\
\hline & Mean & SD & Mean & SD & Mean & SD & Mean & SD & Mean & SD \\
\hline Age (years) & 48 & 7 & 43 & 12 & 42 & 97 & 43 & 10 & 44 & 10 \\
\hline \multirow[t]{2}{*}{ Length of employment (years) } & 24 & 8 & 18 & 12 & 18 & 10 & 18 & 10 & 19 & 10 \\
\hline & $n$ & Column \% & $n$ & Column $\%$ & $n$ & Column \% & $n$ & Column \% & $n$ & Column \% \\
\hline \multicolumn{11}{|l|}{ Gender } \\
\hline Males & 169 & 99.4 & 156 & 98.7 & 150 & 96.8 & 260 & 94.9 & 735 & 97.1 \\
\hline Females & 1 & 0.6 & 2 & 1.3 & 5 & 3.2 & 14 & 5.1 & 22 & 2.9 \\
\hline \multicolumn{11}{|l|}{ Number of cigarettes per day } \\
\hline Non-smokers & 61 & 36.5 & 69 & 44.2 & 69 & 44.8 & 105 & 38.6 & 304 & 40.6 \\
\hline Ex-smokers & 40 & 24.0 & 18 & 11.5 & 33 & 21.4 & 80 & 29.4 & 171 & 22.8 \\
\hline$\leqslant 10$ & 14 & 8.4 & 33 & 21.2 & 15 & 9.7 & 47 & 17.3 & 109 & 14.6 \\
\hline$\leqslant 20$ & 48 & 28.7 & 36 & 23.1 & 33 & 21.4 & 33 & 12.1 & 150 & 20.0 \\
\hline$>20$ & 4 & 2.4 & & - & 4 & 2.6 & 7 & 2.6 & 15 & 2.0 \\
\hline \multicolumn{11}{|l|}{ Amount of alcohol per day } \\
\hline No alcohol intake & 44 & 26.2 & 64 & 41.6 & 24 & 15.5 & 71 & 26.0 & 203 & 27.1 \\
\hline$\leqslant 40 \mathrm{~g}$ & 118 & 70.2 & 63 & 40.9 & 111 & 71.6 & 197 & 72.2 & 489 & 65.2 \\
\hline $40-80 \mathrm{~g}$ & 6 & 3.6 & 27 & 17.5 & 20 & 12.9 & 5 & 1.8 & 58 & 7.7 \\
\hline
\end{tabular}

$\mathrm{SD}$, standard deviation.

concentration throughout the 24 hours in the different parts of the plants where the sampling probes are located. The measurements are carried out every maximum 20 minutes with an air sampling time of two minutes, thus allowing the calculation of daily, weekly, monthly, and yearly averages for each measurement location and area. Levels are then attributed to the jobs based on their time weighted presence in the different areas of the plant.

The above method permitted determination of the yearly average VCM exposure of each worker for each year of his/her service. For the purpose of this study, the following exposure indices were taken into consideration:

- The maximum yearly average VCM concentration value to which the subject was ever exposed in his past work history.

- The cumulative VCM exposure (ppm*years), calculated as the sum of the VCM concentration values of all the individual years.

Collection of past personal health history, lifestyle and personal data, and execution of routine laboratory tests

The medical doctors of each plant made available the personal health history of each worker as documented in his/ her personal medical record. Special attention was paid to the past occurrence of viral hepatitis or other liver diseases.

Personal lifestyle included alcoholic beverage consumption and smoking habits. Plant doctors collected the data by interview. Daily alcohol intake was classified as: no alcohol intake; less than 40 g per day; or 40 to 80 g per day. Smoking groups were defined as non-smokers; ex-smokers; less than 10 cigarettes per day; 10 to 20 cigarettes per day; or more than 20 cigarettes per day.

Height and weight data measured in 1998 were used to calculate the body mass index (BMI) according to the formula: $\mathrm{BMI}=$ weight $[\mathrm{kg}] /$ height $^{2}\left[\mathrm{~m}^{2}\right]$.

Concomitantly to the ultrasonography examination, the following routine tests were performed: red and white blood cell count, haematocrit, haemoglobin concentration, erythrocyte volume, blood glucose level, serum aspartate aminotransferase (AST), serum alanine aminotransferase (ALT), serum $\gamma$-glutamyl transferase (GGT), serum alkaline phosphatase (AP), serum total and conjugated bilirubin, plasma protein electrophoretic pattern, serum cholesterol, and serum triglycerides.

\section{Liver ultrasonography}

The ultrasonography examination was carried out by a different examiner in each of the four plants. In order to ensure comparability of results, a common standard operating procedure for the conduct of the test and a common format of data reporting was defined with the examiners before the start of the survey.

The list of parameters to be systematically evaluated included: liver diameter, liver margin, liver ultrasonographic structure (diffuse hypo- or hyper-reflective echos; hypo- or hyper-reflective focal lesions), portal vein diameter and wall thickness and reflectivity, liver veins, hilum lymphonodes, spleen diameter and ultrasonographic structure, splenic vein, collateral vessels, bile ducts, gallbladder wall, and stones. In addition, the examiners were asked to report on any other findings of interest even if unrelated to the main purpose of this study.

Portal vein wall thickness was measured and graded according to the method recommended by the World Health Organisation to diagnose schistosomiasis related periportal fibrosis. ${ }^{56}$

Hepatomegaly was assessed in accordance with liver diameters reported by Niederau and colleagues. ${ }^{7}$ Longitudinal scans of the liver were obtained in the midclavicular line and midline, measuring the longitudinal diameter. Since in the midclavicular line the upper portion of the liver may be partly masked by the air inside the lung, the margin between the lung and liver was used as the upper limit of the longitudinal diameter. In the midline, the upper margin of the liver under the dome of the diaphragm served as the upper limit of the longitudinal diameter.

Measurements were made during deep inspiration in order to minimise masking by the lung and eliminate morphological variations caused by respiration. The following mean organ diameters were used as reference values:

- Midclavicular longitudinal diameter of the liver: $10.5 \pm 1.5$ $\mathrm{cm}$.

- Midline longitudinal diameter of the liver: $8.3 \pm 1.7 \mathrm{~cm}$.

Measurements exceeding these diameters were labelled as hepatomegaly. 
Table 2 Current job by cumulative and maximum level of VCM exposure in the work history

\begin{tabular}{|c|c|c|c|c|c|c|c|c|c|c|c|c|}
\hline \multirow[b]{3}{*}{ Current job } & \multicolumn{10}{|c|}{ Cumulative VCM exposure (ppm*years) } & & \\
\hline & \multicolumn{2}{|c|}{ Non-exposed } & \multicolumn{2}{|c|}{$1-10$} & \multicolumn{2}{|c|}{$11-100$} & \multicolumn{2}{|c|}{$101-1000$} & \multicolumn{2}{|c|}{$>1000$} & \multicolumn{2}{|l|}{ Total } \\
\hline & $\mathrm{n}$ & Row \% & $\mathrm{n}$ & Row \% & $\mathrm{n}$ & Row \% & $\mathrm{n}$ & Row \% & $\mathrm{n}$ & Row \% & $\mathrm{n}$ & Column \% \\
\hline Managers & 2 & 50 & & & 1 & 25 & 1 & 25 & & & 4 & 0.5 \\
\hline Administrative personnel & 24 & 61.5 & 10 & 25.6 & 2 & 5.2 & 3 & 7.7 & & & 39 & 5.2 \\
\hline Plant operative workers & 6 & 1.2 & 196 & 39.4 & 165 & 33.3 & 71 & 14.2 & 59 & 11.9 & 497 & 65.7 \\
\hline Maintenance workers & & & 40 & 45.4 & 27 & 30.7 & 16 & 18.2 & 5 & 5.7 & 88 & 11.6 \\
\hline Laboratory workers & 47 & 47 & 23 & 23 & 17 & 17 & 9 & 9 & 4 & 4 & 100 & 13.2 \\
\hline \multirow[t]{4}{*}{ Technicians } & 7 & 24.1 & 12 & 41.4 & 2 & 6.9 & 4 & 13.8 & 4 & 13.8 & 29 & 3.8 \\
\hline & \multicolumn{10}{|c|}{ Maximum level of VCM exposure (ppm) } & & \\
\hline & \multicolumn{2}{|c|}{ Non-exposed } & \multicolumn{2}{|c|}{$1-10$} & \multicolumn{2}{|l|}{50} & \multicolumn{2}{|c|}{200} & \multicolumn{2}{|l|}{500} & \multicolumn{2}{|l|}{ Total } \\
\hline & $\mathrm{n}$ & Row \% & $\mathrm{n}$ & Row \% & $\mathrm{n}$ & Row \% & $\mathrm{n}$ & Row \% & $\mathrm{n}$ & Row \% & $\mathrm{n}$ & Column \% \\
\hline Managers & 2 & 50 & 1 & 25 & & & 1 & 25 & & & 4 & 0.5 \\
\hline Administrative personnel & 24 & 61.5 & 11 & 28.2 & 3 & 7.7 & 1 & 2.6 & & & 39 & 5.2 \\
\hline Plant operative workers & 6 & 1.2 & 354 & 71.2 & 49 & 9.8 & 33 & 6.7 & 55 & 11.1 & 497 & 65.7 \\
\hline Maintenance workers & & & 66 & 75 & 7 & 8 & 10 & 11.4 & 5 & 5.7 & 88 & 11.6 \\
\hline Laboratory workers & 47 & 47 & 39 & 39 & 3 & 3 & 7 & 7 & 4 & 4 & 100 & 13.2 \\
\hline Technicians & 7 & 24.1 & 14 & 48.3 & 3 & 10.3 & 2 & 6.9 & 3 & 10.3 & 29 & 3.8 \\
\hline
\end{tabular}

\section{Statistical analysis of data}

To test the significance of various factors, including VCM exposure, as possible determinants of the liver ultrasonography findings, first order logistic regression analyses were carried out. Values of routine laboratory tests were log transformed to obtain a quasi-normal distribution before entering them in the model. VCM exposure variable was considered to be a five level variable and was entered in logistic regression as four binary variables coding for levels 2 to 5 . Therefore the odds ratio obtained refers to the unexposed odds value. Alcohol intake was considered to be a three level variable and was also entered in logistic regression as two binary variables coding for levels 2 and 3. The presence of hepatitis $\mathrm{B}$ or $\mathrm{C}$ in the personal history was coded as $0=$ absent and $\mathrm{l}=$ present.

Statistical analysis was performed using SPSS 10.0 for Windows.

\section{RESULTS}

A total of 757 workers (735 males and 22 females) participated in the study. Table 1 shows the general features of the workers, and their daily consumption of alcohol and smoking status. There were differences in alcohol consumption and smoking habits among factories; this finding would point to possible differences in lifestyle, but it might also be the result of systematic differences in the way the doctors collected this information in the different plants.

Table 2 shows the current job at the time of the study and the indices of VCM exposure, both as cumulative VCM exposure (ppm*years) and maximum yearly average level of VCM exposure in the work history. The most numerous group of workers was represented by workers directly operating on the production plant $(\mathrm{n}=497)$, followed by laboratory workers $(\mathrm{n}=100)$ and maintenance workers $(\mathrm{n}=88)$. Considering the workers with cumulative exposure greater than 100 ppm*years or those with maximum level in the history of 200 and $500 \mathrm{ppm}$, the largest group consisted of personnel directly operating on the plant, while the percentages of laboratory workers, maintenance workers, and technicians were very low. It has to be noted that yearly VCM exposure levels of 200 and $500 \mathrm{ppm}$ were last observed in 1975 and were no longer present after that year.

Table 3 shows the frequency of occurrence of some diseases in the personal history of the workers. Viral hepatitis was present in the health history of 54 workers and was represented by hepatitis B or C in 32 cases and by hepatitis A in 18 cases. The hepatitis A cases were almost all located in the Brindisi plant.

Ultrasonographic examination of the abdomen led to identification of a number of abnormal findings that were unrelated to the scope of the study, including renal cysts, renal benign tumours, urinary tract lithiasis, uterus miomas, etc. Only the results relevant to the liver will be presented.

With regard to focal lesions of the liver, no cases of liver cancer were found. Twenty three cases of single or multiple angiomas $(3.0 \%)$ and 36 cases of liver cysts $(4.7 \%)$ were detected.

With regard to diffuse lesions of the liver, abnormalities were present in a large number of workers. The main findings consisted of hepatomegaly $(34.7 \%)$, hyperreflectivity of the liver parenchyma indicative of steatosis $(31.8 \%)$, and increased thickness and reflectivity of the portal vein wall, indicative of periportal fibrosis (16.0\%). These changes presented singly or associated in the same subject: 25 subjects (3.3\%) showed all three abnormalities together, 19 subjects $(2.5 \%)$ showed hepatomegaly with periportal fibrosis, and 14 subjects $(1.8 \%)$ steatosis with periportal fibrosis. The combination hepatomegaly and steatosis was the most frequent ( 143 subjects, $18.9 \%$ ).

Other ultrasonography findings were at a lower frequency: thickening of the gallbladder wall $7.0 \%$, gallbladder stones $3.6 \%$, splenomegaly $6.2 \%$, and hilum lymphonodes $1.5 \%$.

In order to examine the risk factors associated with the diffuse lesions of the liver, the distributions of hepatomegaly, steatosis, and periportal fibrosis were singly assessed in relation to age, alcohol consumption, body mass index, history of hepatitis, blood laboratory tests, and past VCM exposure. Age as well as alcohol consumption, body mass index, and several blood tests did show an association with the occurrence of liver lesions. With regard to VCM exposure, the only finding that showed a trend towards an increase in accordance with past exposure level was represented by periportal fibrosis.

In order to examine the nature of the association between all these factors and the liver lesions, first order logistic regression analyses were carried out by considering hepatomegaly, steatosis, or periportal liver fibrosis as dependent variables and by entering as independent variables in 


\begin{tabular}{|c|c|c|c|c|c|c|c|c|c|c|}
\hline & \multicolumn{8}{|c|}{ Factory } & & \\
\hline & \multicolumn{2}{|c|}{ Porto Torres } & \multicolumn{2}{|c|}{ Brindisi } & \multicolumn{2}{|c|}{ Ravenna } & \multicolumn{2}{|c|}{ Porto Marghera } & \multicolumn{2}{|l|}{ Total } \\
\hline & $n$ & Column \% & $n$ & Column \% & $\mathrm{n}$ & Column \% & $\mathrm{n}$ & Column \% & $n$ & Column \% \\
\hline \multicolumn{11}{|c|}{ Microcyłemia } \\
\hline Absent & 152 & 96.2 & 144 & 93.5 & 150 & 98.0 & 269 & 98.9 & 715 & 97.0 \\
\hline Present & 6 & 3.8 & 10 & 6.5 & 3 & 2.0 & 3 & 1.1 & 22 & 3.0 \\
\hline \multicolumn{11}{|l|}{ Favism } \\
\hline Absent & 152 & 96.2 & 155 & 100.0 & 152 & 99.3 & 273 & 100.0 & 732 & 99.1 \\
\hline Present & 6 & 3.8 & & & 1 & 0.7 & & & 7 & 0.9 \\
\hline \multicolumn{11}{|c|}{ Diabetes mellitus } \\
\hline Absent & 151 & 95.6 & 154 & 100.0 & 149 & 97.4 & 267 & 98.2 & 721 & 97.8 \\
\hline Present & 7 & 4.4 & & & 4 & 2.6 & 5 & 1.8 & 16 & 2.2 \\
\hline \multicolumn{11}{|c|}{ Viral hepatitis } \\
\hline Absent & 150 & 94.9 & 133 & 85.8 & 148 & 96.7 & 254 & 93.0 & 685 & 92.7 \\
\hline Present & 8 & 5.1 & 22 & 14.2 & 5 & 3.3 & 19 & 7.0 & 54 & 7.3 \\
\hline \multicolumn{11}{|c|}{ Alcoholic hepatitis } \\
\hline Absent & 155 & 98.1 & 154 & 100.0 & 153 & 100.0 & 272 & 100.0 & 734 & 99.6 \\
\hline Present & 3 & 1.9 & & & & & & & 3 & 0.4 \\
\hline
\end{tabular}

sequence: VCM exposure (as cumulative exposure or as maximum yearly level in the work history), age, alcohol consumption class, body mass index, log transformed values of serum triglycerides, log transformed values of GGT , log transformed values of ALT, history of hepatitis B or C. The regression analyses produced the following results.

Hepatomegaly was found to be significantly associated with serum triglycerides, alcohol consumption, and BMI. VCM exposure (either as maximum yearly level in the history or as cumulative exposure) was not significantly related to hepatomegaly ( $\mathrm{p}=0.5-0.6)$. The regression model was highly significant $(p<0.001)$ with $18.5 \%$ of the total variance explained (output not shown).

Steatosis was found to be significantly associated with ALT, serum triglycerides, BMI, and, to a lesser extent, age. VCM exposure (either as maximum yearly level in the history or as cumulative exposure) was not significantly related to steatosis ( $\mathrm{p}$ value $=0.2-0.9)$. The regression model was highly significant $(\mathrm{p}<0.001)$ with $34.8 \%$ of the total variance explained (output not shown).

Periportal fibrosis was found to be highly associated with GGT and maximum level of VCM in the history at the level of $200 \mathrm{ppm}$. Past exposure at $500 \mathrm{ppm}$ was at the border of significance $(p=0.064$, odds ratio (OR) 2.472), while lower exposure levels were not statistically related to the occurrence of periportal fibrosis. The regression model was highly significant $(\mathrm{p}<0.001)$ with $10.3 \%$ of the total variance explained (output shown in table 4). It is interesting to note that the history of hepatitis B or C was not associated with the finding of periportal fibrosis.

The same analysis using cumulative VCM exposure instead of maximum level in the history, provided a similar pattern though with a weaker evidence of association only for cumulative exposure of 100-1000 ppm*years (OR 2.243 versus nonexposed; $\mathrm{p}=0.075)$ and cumulative exposure above 1000 ppm*years (OR 2.486 versus non-exposed; $p=0.059$ ) (output not shown).

Signs indicative of periportal fibrosis were present in 11 subjects ( 10 males and one female) without any exposure to VCM (10\% prevalence). Five of these subjects also had hepatomegaly and steatosis, associated with diabetes and obesity in one case; splenomegaly in one case; high alcohol intake, increased ALT, and history of hepatitis B in one case; increased ALT and AST in one case; and increased serum cholesterol in one case. Of the remaining six cases, one had splenomegaly, one a history of hepatitis B, one was obese, and no apparent abnormal findings were present in three cases.

A further first order logistic regression analysis was carried out by considering GGT, ALT, and serum triglycerides as dependent variables and VCM exposure, age, BMI, and alcohol

Table 4 Regression analysis output for thickened portal vein wall as dependent variable

\begin{tabular}{|c|c|c|c|c|c|}
\hline Variables in the model & Regression coefficent & Standard error & $\begin{array}{l}\text { Degrees of } \\
\text { freedom }\end{array}$ & $p$ value & Relative odds ratio \\
\hline \multicolumn{6}{|l|}{ Max VCM (ppm) } \\
\hline $1-10$ & 0.438 & 0.401 & 1 & 0.276 & 1.549 \\
\hline 50 & 0.433 & 0.520 & 1 & 0.405 & 1.542 \\
\hline 200 & 1.417 & 0.501 & 1 & 0.005 & 4.124 \\
\hline 500 & 0.905 & 0.489 & 1 & 0.064 & 2.472 \\
\hline AGE (years) & 0.023 & 0.015 & 1 & 0.113 & 1.024 \\
\hline \multicolumn{6}{|l|}{ Alcohol intake (g/day) } \\
\hline$\leqslant 40$ & 0.049 & 0.292 & 1 & 0.866 & 1.050 \\
\hline $40-80$ & 0.100 & 0.475 & 1 & 0.832 & 1.106 \\
\hline BMI $\left(\mathrm{kg} / \mathrm{m}^{2}\right)$ & 0.042 & 0.037 & 1 & 0.259 & 1.042 \\
\hline Triglycerides* & 0.646 & 0.442 & 1 & 0.144 & 1.909 \\
\hline GGT* & 1.534 & 0.525 & 1 & 0.004 & 4.637 \\
\hline $\mathrm{ALT}^{*}$ & -0.757 & 0.747 & 1 & 0.311 & 0.469 \\
\hline Hepatitis B/C & -0.317 & 0.577 & 1 & 0.583 & 0.729 \\
\hline Constant & -6.893 & 1.636 & 1 & 0.000 & 0.001 \\
\hline
\end{tabular}

The model included as independent variables in the order: classes of maximum level of VCM exposure in the work history, age, classes of alcohol consumption, body mass index (BMI), serum triglycerides, serum GGT, and serum GPT, presence of hepatitis B/C. ${ }^{*} \log _{10}$ of laboratory results normalised to the upper limit of the normal range. 
consumption as independent variables. The results showed no association between maximum VCM exposure and the dependent variables, which instead were significantly associated with age (GGT and ALT), BMI (all), and alcohol intake (all) (output not shown).

\section{DISCUSSION}

Extensive liver ultrasonography studies on vinyl chloride workers are not present in the literature; this survey is the first study where several hundreds of subjects having a wide range of VCM past exposure levels were systematically investigated and compared with non-exposed subjects. The only other study known is available as an abstract, ${ }^{8}$ and its findings are difficult to evaluate in detail.

This study did not find malignant tumours in any of the investigated subjects. The observed frequency of benign focal lesions (angiomas in 3\% of cases and dysplasic liver cysts in $4.7 \%$ of cases) was within the expected range of the general population," and did not show any association with VCM exposure.

Hepatomegaly and steatosis were observed with a relatively high frequency. The analysis of causative factors indicated that these abnormalities were related to obesity and congenital or dietary lipid metabolism disturbances. VCM exposure was not shown to play any role in the genesis of these lesions.

Periportal fibrosis showed a strong association with GGT increase, an indicator of alcohol intake also sensitive to obesity and lipid metabolism disturbances, and with past VCM exposure, when maximum yearly exposure in the subject's history had been at least $200 \mathrm{ppm}$. Exposure at $500 \mathrm{ppm}$ was at the border of significance, while no effects were observed when exposure was at $50 \mathrm{ppm}$ or lower values.

The risk of periportal fibrosis development in the workers with maximum VCM exposure equal to $200 \mathrm{ppm}$ was found to be about fourfold higher than in the non-exposed workers. The relative potency of past VCM exposure to $200 \mathrm{ppm}$ in inducing such an effect was of the same order of magnitude as the GGT associated metabolic factors.

The nature and health significance of the ultrasonography liver findings detected in these subjects is difficult to assess. Occupational exposure to high VCM concentrations has been associated with an increased risk of liver angiosarcoma. ${ }^{40-22}$ Several epidemiological studies have also pointed to the possible increase of other types of cancer in VCM workers, ${ }^{123-26}$ but the evidence that these other cancers are indeed caused by VCM in man is still controversial. ${ }^{411} 121727$ In addition to cancer, high VCM exposure can induce liver fibrosis, as this lesion has been very often histologically observed in the liver of subjects with angiosarcoma and frequently also in liver biopsy specimens of subjects with exposure above $200 \mathrm{ppm}$ VCM in the absence of any cancer. ${ }^{21}{ }^{28-35}$ VCM induced liver fibrosis is histologically distinguishable from liver cirrhosis because it is mostly confined to the portal spaces and not accompanied by a massive destruction of the lobular structure of the liver as it is typically observed in cirrhosis. Histological pictures of cirrhosis have been described in VCM exposed subjects only rarely, and generally in association with other causes of disease (mainly viral hepatitis). ${ }^{21}{ }^{36}$ The results of the present study, obtained with a non-invasive diagnostic technique, seem to confirm these observations, but should be interpreted with caution.

The gold standard method to diagnose periportal fibrosis is the histopathological examination. There is a limited experience in the detection of periportal fibrosis by extensive use of ultrasonography and it relates mainly to investigations of schistosomiasis mansoni patients. Periportal fibrosis is a major complication of schistosomiasis as the granuloma cell populations produce fibroblast stimulation factors, fibroblast growth factors, and other substances which stimulate fibrinogenesis with subsequent collagen deposition in the portal tract. ${ }^{37}$ The
World Health Organisation ${ }^{5}$ established two methods for diagnosis of schistosomiasis related periportal fibrosis by the use of ultrasonography: a descriptive method which takes into account the liver texture as a whole, ${ }^{38} 39$ and a quantitative method involving the measurements of the thickness of the walls of branches of the portal vein. ${ }^{6}$ Abdel-Wahab et $a l^{40}$ reported the sensitivity and specificity of ultrasound in diagnosing schistosomal periportal fibrosis to be $97 \%$ and $95 \%$, respectively, when compared with histopathology.

The sonographic appearance of non-cirrhotic portal fibrosis was evaluated in a case-control study. The ultrasonographic finding seen in all cases was the presence of hyperechoic bands sorrounding the dilated portal vein and its branches. Microscopic examination of the liver biopsy specimens showed a relatively well preserved lobular architecture. The dominant histological abnormality was a prominent fibrous thickening around the portal vein and its branches. ${ }^{41}$ A case study reported the presence of well demarcated bands of increased echogenicity surrounding the portal tracts. Subsequent postmortem examination revealed several large and medium sized portal tracts in both liver lobes with an increased fibrous connective tissue. The authors concluded that the sonographic images were very similar to those described as being specific for schistosomiasis mansoni periportal fibrosis. ${ }^{42}$ It seems plausible to suggest that the portal vein wall thickening observed in our VCM workers can be most likely attributed to periportal fibrosis, although a definitive confirmation of this diagnosis would require histopathological examination.

The increased frequency of periportal fibrosis observed in the workers exposed at or above $200 \mathrm{ppm}$ probably represents the expression of a toxic effect directly induced by VCM in some of the exposed subjects. The fact that the maximum yearly VCM exposure level in the past history proved to be a better predictor of periportal fibrosis than the cumulative VCM exposure index, suggests that a minimum intensity of exposure is necessary for this action by VCM (200 ppm for one year), and such a toxicological threshold cannot be reached even by a prolonged exposure at lower level.

The presence of ultrasonographic signs of periportal fibrosis in 11 subjects never exposed to VCM seems to indicate that these lesions are not specific to toxic exposures. Some of these subjects had other metabolic disorders or associated findings that could explain the presence of fibrosis. However three subjects did not have any associated condition and their findings deserve further confirmatory investigations.

This survey was initiated to address the health concern for the workers that in the past may have had high exposure to VCM and to assess the possibility of improving the diagnostic efficacy of the routine medical surveillance of the workers. Liver ultrasonography, carried out with a standardised protocol, proved to be a sensitive diagnostic technique, able to reveal morphological changes of liver structure previously unknown in these subjects. In consideration of its diagnostic value, this test can be conveniently adopted for the medical surveillance of VCM workers and will be used for a follow up of the findings of this survey.

\section{ACKNOWLEDGEMENTS}

This study was performed with the substantial contribution of the EVC plant doctors, namely Dr N Greco, Marghera; Dr C Benedetti, Ravenna; Dr F Mocci, Porto Torres; and Dr Finnizzi, Brindisi. The liver ultrasonography examinations were respectively executed by Drs P Wolf, F Fusconi, A Paoni, and E Piva.

\section{Authors' affiliations}

M Maroni, G Preti, Department of Occupational Medicine, School of Medicine and Surgery, University of Milan, Italy

F Mocci, Chair of Occupational Medicine, School of Medicine and Surgery, University of Sassari, Italy 
S Visentin, A C Fanetti, International Centre for Pesticides and Health Risk Prevention, World Health Organisation, University of Milan, Region of Lombardy, Busto Garolfo, Milan, Italy

\section{REFERENCES}

1 Belli S, Bertazzi PA, Comba P, et al. A cohort study of vinyl chloride manufacturers in Italy: study design and preliminary results. Cancer Lett 1987;35:253-61.

2 Pirastu R, Belli S, Bruno $C$, et al. La mortalità dei produttori di cloruro di vinile in Italia. Med Lav 1991:82:388-423.

3 Pirastu R, Comba P, Reggiani A, et al. Mortality from liver disease among Italian vinyl chloride/polyvinyl chloride manufacturers. Am J Industr Med 1990;17:155-61.

4 Simonato L, L'Abbe KA, Andersen A, et al. A collaborative study of cancer incidence and mortality among vinyl chloride workers. Scand J Work Environ Health 1991;17:159-69.

5 WHO. Ultrasound in schistosomiasis. A practical guide to the standardized use of ultrasonography for the assessment of schistosomiasis-related morbidity. Second international workshop, 22-26 October 1996, Niamey, Niger.

6 Abdel-Wahab MF, Esmat G, Farrag A, et al. Grading of hepatic schistosomiasis by the use of ultrasonography. Am J Trop Med Hyg 1992;46:403-8.

7 Niederau C, Sonnenberg A, Müller J, et al. Sonographic measurements of the normal liver, spleen, pancreas, and portal vein. Radiology 1983; 149:537-40

8 Hsiao TJ, Yang PM, Yang PJ, et al. Asymptomatic chronic liver disease in PVC workers. Proceedings of the 26th International Congress on Occupational Health, 27 August to 1 September, Singapore.

9 Fauci AS et al, eds. Harrison's principles of internal medicine, 14th edn. New York: McGraw-Hill, 1998.

10 WHO. International Programme on Chemical Safety. Environmental Health Criteria. No. 215, Vinyl Chloride. Geneva: WHO, 1999

11 Mundt KA, Dell LD, Austin RP, et al. Epidemiological study of men employed in the vinyl chloride industry between 1942 and 1972: I. Re-analysis of mortality through December 31, 1982; and II. Update of mortality through December 31, 1995. Final Report. Amherst: Applied Epidemiology Inc., 1999

12 Ward E, Boffetta P, Andersen A, et al. Update of the follow-up of mortality and cancer incidence among European workers employed in the vinyl chloride industry. Lyon: IARC, 2000

13 European Centre for Ecotoxicology and Toxicology of Chemicals. The mutagenicity and carcinogenicity of vinyl chloride: A historical review and assessment. Technical report no. 31. Brussels: ECETOC, 1988.

14 Laplanche A, Clavel-Chapelon F, Contassot J-C, et al. Exposure to vinyl chloride monomer: results of a cohort study after a seven year follow up. Br J Industr Med 1992:49:134-7.

15 Hagmar L, Akesson B, Nielsen J, et al. Mortality and cancer morbidity in workers exposed to low levels of vinyl chloride monomer at a polyvinyl chloride processing plant. Am J Industr Med 1990;17:155-61.

16 Jones RD, Smith DM, Thomas PG. A mortality study of vinyl chloride monomer workers employed in the United Kingdom in 1940-1974. Scand J Work Environ Health 1988;14:153-60

17 Wong $\mathrm{O}$, Whorton MD, Foliart DR, et al. An industry-wide epidemiologic study of vinyl chloride workers, 1942-1982. Am J Industr Med 1991;20:317-34.

18 Wu W, Steenland K, Brown D, et al. Cohort and case-control analyses of workers exposed to vinyl chloride: an update. J Occup Med 1989;31:518-23.

19 International Agency for Research on Cancer. Overall evaluations of carcinogenicity: an updating of IARC monographs, Volumes 1-42. IARC monographs on the evaluation of carcinogenic risks to humans, suppl. 7 . Lyon: IARC, 1987.
20 Doll R. Effects of exposure to vinyl chloride. Scand I Work Environ Health 1988;14:61-78.

21 Du C-L, Wang J-D. Increased morbidity odds ratio of primary liver cancer and cirrhosis of the liver among vinyl chloride monomer workers. Occup Environ Med 1998:55:528-32.

22 Forman D, Bennet B, Stafford J, et al. Exposure to vinyl chloride and angiosarcoma of the liver: a report of the register of cases. Br J Industr Med 1985;42:750-3

23 Buffler PA, Wood S, Eifler C, et al. Mortality experience of workers in a vinyl chloride monomer production plant. J Occup Med 1979;21:195-203.

24 Weber H, Reinl W, Greiser E. German investigations on morbidity and mortality of workers exposed to vinyl chloride. Environ Health Perspect 1981:41:95-9.

25 Smulevich VB, Fedotova IV, Filatova VS. Increasing evidence of the rise of cancer in workers exposed to vinyl chloride. Br J Industr Med 1988;45:93-7.

26 Saurin JC, Taniere P, Mion F, et al. Primary hepatocellular carcinoma in workers exposed to vinyl chloride: a report of two cases. Cancer 1997;79:1671-7.

27 McLaughlin JK, Lipworth L. A critical review of the epidemiologic literature on health effects of occupational exposure to vinyl chloride. J Epidemiol Biost 1999:4:253-75.

28 Smith PM, Crossley IR, Williams M. Portal hypertension in vinyl-chloride production workers. Lancet 1976;ii:602-4.

29 Berk PD, Martin JF, Young RS et al. Vinyl chloride-associated liver disease. Ann Intern Med 1976:84:717-31.

30 Lee FI, Harry DS, Adams WGF, et al. Screening for liver disease in vinyl chloride workers. Br J Industr Med 1977;34:142-7.

31 Blendis LM, Smith PM, Lawrie BW, et al. Portal hypertension in vinyl chloride monomer workers. A hemodinamic study. Gastroenterology 1978;75:206-1 1.

32 Koischwitz VD, Lelbach WK, Lacker K, et al. Vinylchloridiinduzierte leberangiosarkom und hepatozellulare karzinom. Forschr Rongtenstr $1981 ; 134: 283-90$

33 Popper H, Thomas LB, Telles NC, et al. Development of hepatic angiosarcoma in man induced by vinyl chloride, thorotrast and arsenic. Am J Pathol 1978;92:349-69.

34 Popper H, Maltoni C, Selikoff IG. Vinyl chloride-induced hepatic lesions in man and rodents. A comparison. Liver 1981;1:7-20.

35 Tamburro $\mathbf{C H}$, Makk L, Popper $\mathrm{H}$. Early hepatic histologic alterations among chemical (vinyl monomer) workers. Hepatology 1984;4:413-18.

36 Lelbach W. A 25-year follow-up study of heavily exposed vinyl chloride workers in Germany. Am J Industr Med 1996;29:446-58.

37 Prakash S, Wyler DJ. Fibroblast stimulation in schistosomiasis. XI. Purification to apparent homogeneity of fibroblast-stimulating factor-1, an acidic heparin-binding growth factor produced by schistosomal egg granulomas. J Immunol 1991;146:1679-84.

38 Homeida M, Abdel-Gadir AF, Cheever AW, et al. Diagnosis of pathologically confirmed Symmer's periportal fibrosis by ultrasonography: a prospective blinded study. Am J Trop Med Hyg 1988;38:86-91.

39 Doehring-Schwerdtfeger E, Mohamed-Ali G, Abdel-Rahim IM, et al. Sonographical abnormalities in Sudanese children with Schistosoma mansoni infection. A proposed staging system for field diagnosis of periportal fibrosis. Am J Trop Med Hyg 1989;41:63-9.

40 Abdel-Wahab MF, Esmat G, Farrag A, et al. Characteristic sonographic pattern of schistosomal hepatic fibrosis. Am J Trop Med Hyg 1989:40:72-6.

41 Gürkaynak G, Yildirim B, Aksoy F, et al. Sonographic findings in noncirrhotic portal fibrosis. J Clin Ultrasound 1998;26:309-13.

42 Michielsen P, Pelckmans PA, Van Maercke Y, et al. Hepatoportal sclerosis demonstrated by abdominal ultrasonography. J Clin Ultrasound $1991 ; 19: 513-15$. 